\title{
ASSESSMENT OF THE CO-INCIDENCE BETWEEN NON ALCOHOLIC FATTY LIVER DISEASE AND CAROTID ATHEROSCLEROSIS
}

\author{
By \\ SOHAIR ABD EL- KADER EL-SAYED ${ }^{1}$, RUNIA FOUAD EL-FOLLY ${ }^{1^{*}}$ \\ and AMR MAHMMOUD AHMED ${ }^{2}$ \\ Department of Tropical Medicine ${ }^{1}$ and Department of Radiology ${ }^{2}$, \\ Faculty of Medicine, Ain Shams University, Cairo 11341, Egypt \\ Correspondence*: Email: runiaelfollytm@yahoo.com \\ Mobile: +2 01223943516; Fax: +2 0226820665
}

\begin{abstract}
Non-alcoholic fatty liver disease (NAFLD) is currently the most common cause of abnormal liver biochemistry and cryptogenic cirrhosis. Those with NAFLD have a higher prevalence of atherosclerosis, as shown by increased carotid artery intimal media thickness (CIMT). The aim of this study is to assess the co-incidence and prevalence between NAFLD and carotid atherosclerosis.

In this study seventy-two subjects were categorized into 2 groups. GI: 52 patients diagnosed as NAFLD with diabetes mellitus type 2 or obesity or hyperlipedemia. GII: 20 diseased controls diagnosed as NAFLD without other predisposing factor. CIMT and plaque prevalence were estimated by carotid ultrasonography as a single trained operator who was blind to clinical characteristics of participants.

The results showed that CIMT by carotid duplex ultrasonography was significantly higher in group A than group B but CIMT did not reveal any significant difference as regards to the etiology of NAFLD. CIMT was significantly higher in cases with bright liver than those with homogenous liver (by abdominal US) in group I and II. CIMT was significantly higher in those with moderate steatosis than those with mild steatosis (in GI \& GII).
\end{abstract}

Key words: Non-alcoholic fatty liver disease; Coronary heart disease; Carotid intimal media thickness.

\section{Introduction}

Non-alcoholic fatty liver disease (NAFLD), as conventionally recognized is a metabolic disorder largely confined to residents of affluent industrialized western countries, however, obesity and insulin resistance; the common substrates of NAFLD are not restricted to the west as witnessed by their increasingly universal distribution (Williams, 2006). The prevalence of NAFLD in general population ranges from $5 \%$ to $33 \%$. Up to more than $75 \%$ of obese adult subjects can be affected by NAFLD (Farrell and Larter, 2006).

The prevalence of NAFLD has grown to epidemic proportions; it is currently the most common cause of abnormal liver biochemistry and cryptogenic cirrhosis, and a frequent indication for liver transplantation (Clark, 2006). In one study, patients with NASH had significantly reduced survival compared to the general population and a higher risk of liver-related ( $2.8 \%$ vs. $0.2 \%)$ and cardiovascular death $(15.5 \%$ vs. $7.5 \%)$ (Ekstedt et al, 2006). Thus, NAFLD shares many features of the metabolic syndrome (MetS), a highly atherogenic condition (Grundy et al, 2004). The potential cardiovascular risk associated with NAFLD has not been particularly investigated, despite the evidence that mortality rates from coronary heart disease (CHD) equaled those at- 
tributable to cirrhosis in a large cohort of patients with biopsy-proven NAFLD followed for up to 18 years (Matteoni et al, 1999).

The aim of this study was to assess the coincidence and prevalence between the NAFLD (\& its etiology) and carotid atherosclerosis as a cardiovascular risk factor.

\section{Patients, Materials and Methods}

This cross sectional study has been performed in accordance with the ethical standards. Informed consents were obtained from all participants before enrollment in the study. Right to refuse participation was emphasized.

This study included 72 cases which were divided into two groups: GI: Formed of 52 patients diagnosed as NAFLD with diabetes mellitus type 2 or obesity or hyperlipedemia. GII: Diseased control formed of 20 cases diagnosed as NAFLD without other predisposing factor.

Inclusion criteria: Clinical, biochemical, and sonographical criteria of NAFLD for (GI \& GII). The presence of steatosis in ultrasound scan with or without elevated ALT and $\backslash$ or AST, negative or occasional historic alcohol intake (<140gm $\backslash$ week), negative diagnosis of other causes liver diseases (HAV, $\mathrm{HBV}, \mathrm{HCV}$, autoimmune hepatitis and metabolic liver disease) (Rocha et al, 2009), as well as, For GI; Elevated FBS ( $\geq 126 \mathrm{mg} / \mathrm{dl}$ ) and $2 \mathrm{hr} \mathrm{PP} \mathrm{(} \geq 200 \mathrm{mg} / \mathrm{dl})$ (WHO, 2006). Elevated lipid profile (cholesterol $>200 \mathrm{mg} / \mathrm{dl}$, $\mathrm{TG}>160 \mathrm{mg} / \mathrm{dl}$ for male and $>135 \mathrm{mg} / \mathrm{dl}$ for female, LDL $>130 \mathrm{mg} / \mathrm{dl}, \mathrm{HDL}<29 \mathrm{mg} / \mathrm{dl}$ for male and $<35 \mathrm{mg} / \mathrm{dl}$ for female) according to the Egyptian lab. and $\backslash$ or Elevated BMI (whereas $\mathrm{BMI}<18.5$ was underweight, $\mathrm{BMI}<25$ is normal, $\mathrm{BMI} \geq 25$ is overweight (pre-obese), BMI $>30$ was obese) (WHO, 2010).

Eligibility Criteria: Male \& female patients with NAFLD, age in both groups were above age of 20 years old and below age of 50 years. Exclusion criteria: Other causes of chronic liver disease and steatosis, alcoholic patients and patients with advanced systemic disease as heart failure or any debilitating disease that will affect life expectancy.

All the enrolled patients were subjected to: alanine transaminases, aspartate transaminases, serum albumin, serum bilirubin (total and direct), prothrombin time and international normalization ratio (INR), hepatitis markers (HCV antibody (using third generation ELISA test), hepatitis B surface antigen (using second generation ELISA test), and hepatitis B coreIgG), lipid profile (serum cholesterol, LDL, HDL, and serum triglyceride), glucose profile (fasting blood sugar, 2 hours postprandial, $\mathrm{HbAlc}$ in diabetic patient).

Abdominal ultrasonography (a real time scanning device Ezaote-Technos with convex probe, $3.5 \mathrm{MHz}$ ): Following the American gastroenterological association (AGA) classification of NAFLD steatosis was defined as the presence of diffuse hyper-echoic echo-texture (Sanyal, 2002). Bright liver increased liver echo-texture compared with the kidneys, vascular blurring and deep attenuation of the ultrasonic beam (Palmentieri et $a l, 2006)$.

Carotid ultrasonography (a real time scanning device Ezaote-Technos with Linear probe, $10 \mathrm{MHz}$ ): Carotid intimal media thickness (CIMT) and plaque prevalence were estimated by carotid ultrasonography (Choi et al, 2008), by a single trained operator who was blind to clinical characteristics of participants.

Carotid IMT measurements (which are normally less than $1.1 \mathrm{~mm}$ ) (William and Clyde, 2007) were made bilaterally at the level of the common carotid artery for the wall and always in stenotic-free segments.

The ultrasound guided liver biopsy (if possible) and histopathological examina-tion: 26 patients with the pre-designed inclusion criteria were subjected to liver biopsy (one of the limitation of this study is that the diagnosis of NAFLD was based on medical history, laboratory investigations and ultrasound imaging but was not confirmed by 
liver biopsy, as most of the cases refused to do biopsy).

All taken biopsies were guided by imaging (ultrasonography) techniques after adjustment of prothrombin time and platelet count.
The histopathological examination; was performed in order to assess the steatosis level according to (Brunt et al, 1999) [None (0\%), Mild (>5\%), moderate (10-50\%), sever $(50 \%)]$.

Grading and Staging of NAFLD

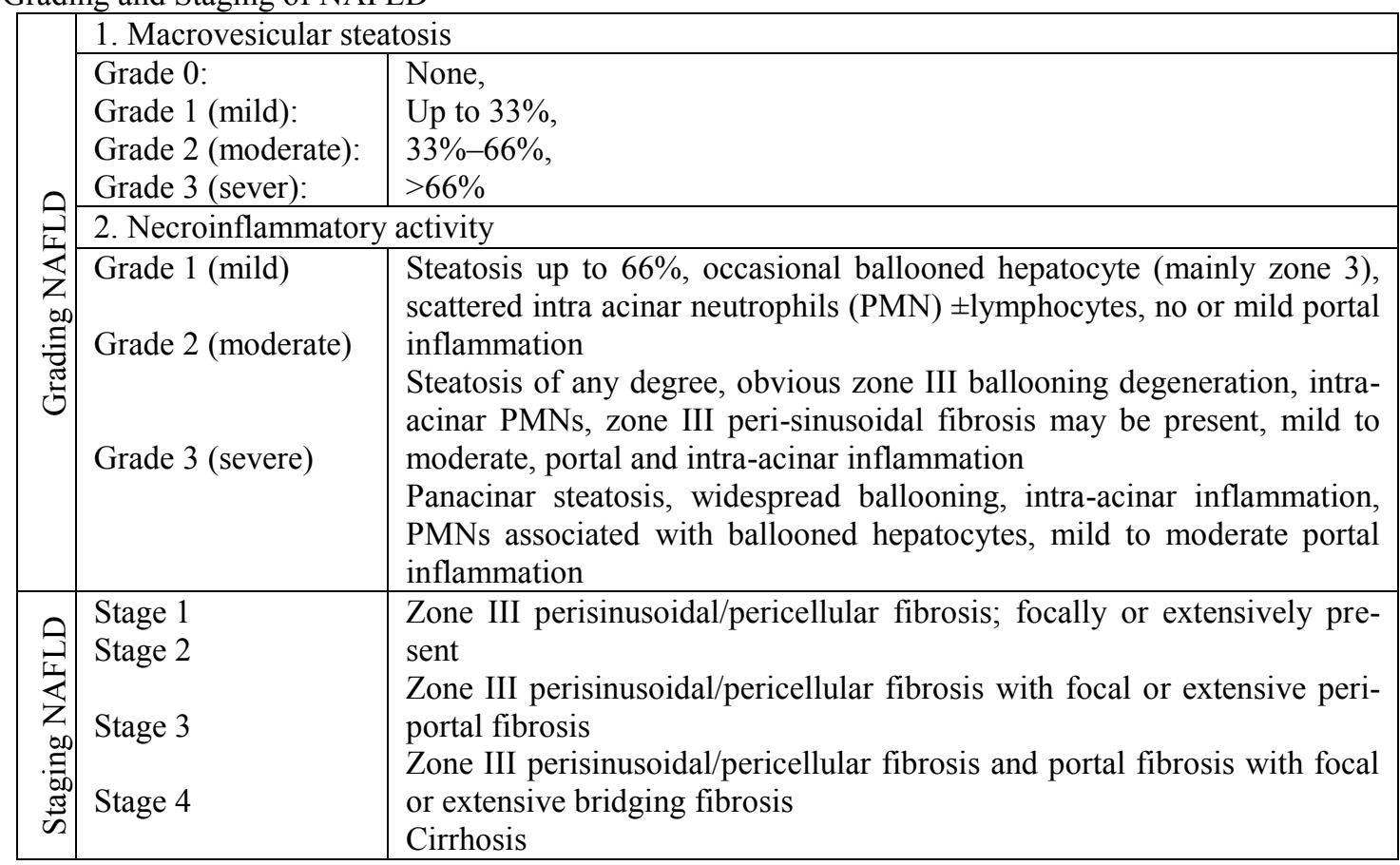

Brunt et al. (1999)

Statistical analysis: Data were processed and analyzed using the statistical package for social sciences (SPSSV. 15.2, Echosoft Corp., USA, 2006) program. Data were expressed as Mean \pm standard deviation (SD) for quantitative measures and both number and percentage for categorized data. The following tests were used: Student's t-test of two independent variables, Chi-square test, Fisher's exact test and McNemar test. Correlation co-efficient test (r-test) was used to rank different variables against each other either directly or indirectly. Significance level $(\mathrm{P})$ value was expressed as follows: $\mathrm{P}$ $>0.05=$ Insignificant, $\mathrm{P}<0.05=$ Significant, $\mathrm{P}<0.01=$ highly significant.

\section{Results}

Both groups were well-matched regarding age and sex, as well as hepatomegaly and obesity (BMI) were significantly more frequent in-GI. There was a statistically significant difference regarding $\mathrm{Hb}$ and platelets as well as ALT, AST and albumin between GI \& GII (Tab. 1). This result could be explained as the additive risks of DM in group A (NAFLD with DM) let GI had worsen liver condition than GII (NAFLD only). By abdominal US, Hepatomegaly was significantly more frequent in GI than GII $(\mathrm{P}<0.05)$, shown (Tab. 2). 
Table 1: Comparison between Gs I \& II as regards age, sex, clinical signs and laboratory investigations:

\begin{tabular}{|c|c|c|c|c|c|c|}
\hline \multicolumn{2}{|c|}{ Variables } & GI $(\mathrm{N}=52)$ & GII $(\mathrm{N}=20)$ & $t^{\wedge} / \chi^{2 \#}$ & $\mathrm{p}$ & Sig. \\
\hline \multicolumn{2}{|c|}{ Age (yrs) } & $35.8 \pm 6.2$ & $35.0 \pm 5.6$ & $1.547^{\wedge}$ & $>0.050$ & NS \\
\hline \multicolumn{2}{|c|}{$\begin{array}{l}\text { Female } \\
\text { Male }\end{array}$} & $\begin{array}{l}15(28.8 \%) \\
37(71.2 \%)\end{array}$ & $\begin{array}{c}4(20.0 \%) \\
16(80.0 \%)\end{array}$ & $0.582^{\#}$ & 0.446 & NS \\
\hline \multirow{3}{*}{ 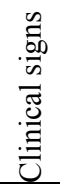 } & BMI (kg/m2) & $30.9 \pm 3.1$ & $27.0 \pm 1.5$ & $7.092^{\wedge}$ & $<0.001$ & HS \\
\hline & \multirow{2}{*}{\begin{tabular}{ll}
\multicolumn{2}{l}{ Hepatomegaly } \\
- & Tender \\
- & Non tender
\end{tabular}} & $36(69.2 \%)$ & $6(30.0 \%)$ & $7.995^{\#}$ & $<0.050$ & $\mathrm{~S}$ \\
\hline & & $\begin{array}{c}28(77.8 \%) \\
8(22.2 \%)\end{array}$ & $\begin{array}{l}4(66.7 \%) \\
2(33.3 \%)\end{array}$ & $0.350^{\#}$ & $>050$ & NS \\
\hline \multirow{3}{*}{ O } & HGB (gm/dl) $(12-16 \mathrm{~g} / \mathrm{dl})$ & $12.2 \pm 1.7$ & $14.4 \pm 1.4$ & $-5.129^{\wedge}$ & $<0.001$ & $\mathrm{HS}$ \\
\hline & WBC $\left(x 10^{3} / \mathrm{cm}^{2}\right)(4-11$ cells $/ \mathrm{mm} 3)$ & $6.8 \pm 0.8$ & $6.3 \pm 1.6$ & $1.273^{\wedge}$ & $>0.05$ & NS \\
\hline & Platelets $\left(\mathrm{x} 10^{3} / \mathrm{cm}^{2}\right)(150-400 / \mathrm{mm} 3)$ & $234.4 \pm 48.2$ & $260.8 \pm 48.1$ & $-2.080^{\wedge}$ & $<0.05$ & $\mathrm{~S}$ \\
\hline \multirow{5}{*}{ 兒 } & ALT (IU) Up to(37 IU/L) & $41.1 \pm 30.3$ & $22.8 \pm 6.4$ & $4.106^{\wedge}$ & $<0.05$ & $\mathrm{~S}$ \\
\hline & AST (IU) Up to(40 IU/L) & $29.2 \pm 13.9$ & $21.4 \pm 6.5$ & $3.239^{\wedge}$ & $<0.05$ & $\mathrm{~S}$ \\
\hline & Albumin $(\mathrm{mg} / \mathrm{dl})(3.5-5 \mathrm{mg} / \mathrm{dl})$ & $3.9 \pm 0.5$ & $4.6 \pm 0.5$ & $-5.815^{\wedge}$ & $<0.001$ & $\mathrm{HS}$ \\
\hline & T. bil (mg/dl) Up to(1.2mg/dl) & $0.69 \pm 0.20$ & $0.67 \pm 0.22$ & $0.398^{\wedge}$ & $>0.05$ & NS \\
\hline & D.bil $(\mathrm{mg} / \mathrm{dl})(0.3 \mathrm{mg} / \mathrm{dl}))$ & $0.19 \pm 0.09$ & $0.15 \pm 0.07$ & $1.662^{\wedge}$ & $>0.05$ & NS \\
\hline
\end{tabular}

${ }^{\wedge}$ Independent t-test; \#Chi Square test

Table 2: Comparison between Gs I \& II as regards abdominal Ultrasonography:

\begin{tabular}{|l|c|c|c|c|c|}
\hline Variables & GI $(\mathrm{N}=52)$ & GII $(\mathrm{N}=20)$ & $\chi 2 \#$ & $p$ & Sig. \\
\hline Liver echogenicity & & & & & \\
$\bullet \quad$ Homogenous & $13(25.0 \%)$ & $9(45.0 \%)$ & 2.723 & $>0.05$ & NS \\
$\bullet \quad$ Bright & $39(75.0 \%)$ & $11(55.0 \%)$ & & & \\
\hline Hpatomegaly $(>15 \mathrm{~cm}) *$ & $36(69.2 \%)$ & $6(30.0 \%)$ & 9.146 & $<0.05$ & S \\
\hline Splenomegaly $(>13 \mathrm{~cm})^{* *}$ & $2(3.8 \%)$ & $0(0.0 \%)$ & 0.791 & $>0.05$ & NS \\
\hline GB stone & $12(23.1 \%)$ & $2(10.0 \%)$ & 1.577 & $>0.05$ & NS \\
\hline P.V. diameter $(\leq 13 \mathrm{~mm}) * * *$ & $11.7 \pm 0.6$ & $11.3 \pm 0.5$ & 2.263 & $>0.05$ & NS \\
\hline
\end{tabular}

\#Chi Square test, * Kuntz, E, Dieter, H, (2006), ** Bates, JA, (2004), *** Olliff, JF, (2003).

Table 3: Comparison between groups as regards carotid duplex ultrasonography

\begin{tabular}{|l|c|c|c|c|c|}
\hline Variables & GI $(\mathrm{N}=52)$ & GII $(\mathrm{N}=20)$ & $\mathrm{t}^{\wedge}$ & $\mathrm{p}$ & Sig. \\
\hline Atheromatus plaque & $0(0.0 \%)$ & $0(0.0 \%)$ & -- & -- & \\
\hline Carotid intimal thickness (CIMT) $(\mathrm{mm})$ & $0.72 \pm 0.14$ & $0.63 \pm 0.18$ & 2.053 & 0.044 & $\mathrm{~S}$ \\
\hline
\end{tabular}

Table 4: Correlation between carotid intimal thickness \& different parameters in Gs:

\begin{tabular}{|l|c|c|c|c|c|c|}
\hline \multirow{2}{*}{ Variables } & \multicolumn{3}{|c|}{ GI $(\mathrm{N}=52)$} & \multicolumn{3}{c|}{ GII (N=20) } \\
\cline { 2 - 7 } & $\mathrm{r}^{\wedge}$ & $\mathrm{p}$ & $\mathrm{Sig}$. & $\mathrm{r}^{\wedge}$ & $\mathrm{p}$ & Sig \\
\hline Age & 0.245 & 0.080 & $\mathrm{~S}$ & 0.200 & 0.398 & $\mathrm{NS}$ \\
\hline BMI & 0.229 & 0.103 & $\mathrm{NS}$ & 0.191 & 0.420 & $\mathrm{NS}$ \\
\hline ALT & 0.004 & 0.980 & $\mathrm{NS}$ & -0.027 & 0.910 & $\mathrm{NS}$ \\
\hline AST & 0.163 & 0.248 & $\mathrm{NS}$ & -0.006 & 0.980 & $\mathrm{NS}$ \\
\hline Albumin & -0.331 & 0.016 & $\mathrm{~S}$ & 0.144 & 0.546 & $\mathrm{NS}$ \\
\hline Cholesterol & 0.166 & 0.241 & $\mathrm{NS}$ & 0.250 & 0.287 & $\mathrm{NS}$ \\
\hline Triglycerides & -0.015 & 0.917 & $\mathrm{NS}$ & 0.069 & 0.774 & $\mathrm{NS}$ \\
\hline FBS & 0.189 & 0.180 & $\mathrm{NS}$ & 0.359 & 0.120 & $\mathrm{NS}$ \\
\hline 2hPPBS & 0.177 & 0.209 & $\mathrm{NS}$ & 0.337 & 0.146 & $\mathrm{NS}$ \\
\hline HBA1c \# & 0.847 & 0.001 & $\mathrm{HS}$ & -- & - & $\mathrm{NS}$ \\
\hline P.V. diameter & -0.026 & 0.856 & $\mathrm{NS}$ & -0.118 & 0.621 & NS \\
\hline
\end{tabular}

\# in diabetic cases $(n=13) \wedge$ Pearson correlation 
Table 5: Comparison between US findings and CIMT:

\begin{tabular}{|c|c|c|c|c|c|c|c|}
\hline Variables & Group & & $\mathrm{N}$ & $\mathrm{M} \pm \mathrm{SD}$ & $\mathrm{t}^{\wedge}$ & $\mathrm{p}$ & Sig. \\
\hline \multirow{4}{*}{ 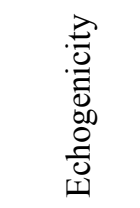 } & \multirow[t]{2}{*}{ GI } & Homogenous & 13 & $0.60 \pm 0.17$ & \multirow{2}{*}{3.930} & \multirow{2}{*}{$<0.001$} & \multirow{2}{*}{ HS } \\
\hline & & Bright & 39 & $0.76 \pm 0.11$ & & & \\
\hline & \multirow{2}{*}{ GII } & Homogenous & 9 & $0.49 \pm 0.11$ & \multirow{2}{*}{-4.368} & \multirow{2}{*}{$<0.001$} & \multirow{2}{*}{ HS } \\
\hline & & Bright & 11 & $0.75 \pm 0.15$ & & & \\
\hline \multirow{4}{*}{ 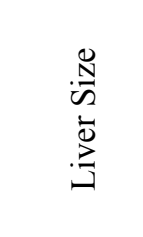 } & \multirow[b]{2}{*}{ GI } & Enlarged & 36 & $0.71 \pm 0.15$ & \multirow{2}{*}{-0.969} & \multirow{2}{*}{0.337} & \multirow{2}{*}{ NS } \\
\hline & & Average & 16 & $0.75 \pm 0.12$ & & & \\
\hline & \multirow{2}{*}{ GII } & Enlarged & 6 & $0.69 \pm 0.14$ & \multirow{2}{*}{0.912} & \multirow{2}{*}{0.374} & \multirow{2}{*}{ NS } \\
\hline & & Average & 14 & $0.61 \pm 0.20$ & & & \\
\hline
\end{tabular}

Independent t-test

Regarding liver echogenicity, bright liver is more common than homogenous (normal) liver in GI than GII but without any significant difference $(\mathrm{P}>0.05)$.

Liver biopsies were taken from 6 cases of NAFLD with predisposing factors (only $3 \%$ had mild steatosis and 3\% with moderate steatosis) and 20 cases of the control group NAFLD without predis-poseing factors (60\% had mild steatosis and $40 \%$ with moderate steatosis). There is no statistically significant difference between both groups as regards grades of steatosis by liver biopsy, as only 6 cases in GI and 20 cases in GII (Fig. 1), that was mostly due to limited number of cases that agreed to do liver biopsy.

The Carotid intimal thickness was significantly higher in- GI than GII, and no atheromatus plaque in both groups (Tab. 3). This result denotes that group A which had high BMI, had a significantly higher CIMT, clarifying that the cause of increased CIMT is due to causes pertain to GI specifically (DM and lor hyperlipedimia) with obesity itself.

Using ranked Spearman correlation test carotid intimal thickness in group A had a significant negative correlation with albumin and positive correlation with HBA1c (Tab. 4). This result also could explain that the albumin and HBA1C are parameters of DM control, so increased serum HBA1C and decreased serum albumin, represented the deterioration of DM control which increased the risk for high CIMT in GI, and this phe- nomena was not apparent in GII due to absence of such risks that were presented in GI, denoting that there were difference between GI \& GII in risks that caused difference of outcome.

As expected, CIMT was significantly higher in cases with bright liver than those with homogenous liver in GI and GII, without significant difference bet-ween liver sizes and CIMT (Tab. 5). There was no significant difference bet- ween CIMT and the NAFLD etiology (obese and hyperlipedimic cases) (Fig. 2). CIMT was significantly higher in GI \& GII patients with moderate steatosis than those with mild steatosis (Fig. 3).

\section{Discussion}

No doubt, non-alcoholic fatty liver disease (NAFLD) is increasingly diagno-sed worldwide and considered to be the commonest liver disorder in clinical practice. It comprises a disease spectrum from variable degrees of simple steatosis to non-alcoholic steatohepatitis (NASH), cirrhosis and hepatocellular carcinoma (Preiss and Sattar, 2008). In Egypt, one study was done about NAFLD in obese Egyptian children; the prevalence of NAFLD was $19.7 \%$ (10.5\% was simple steatosis and $9.2 \%$ was NASH (Chitturi et al, 2011).

NAFLD is strongly associated with insulin resistance, obesity, hypertension, and dyslipidemia and is now regarded as the liver manifestation of the metabolic syndrome (Marchesini and Marzocchi, 2007). Subjects 
with NAFLD have a higher prevalence of atherosclerosis, as shown by increased carotid artery intimal media thickness (CIMT), numbers of atherosclerotic plaques, and circulating markers of endothelial dysfunction (Fracanzani et al, 2008). Although an indirect association between NAFLD and cardiovascular disease (CVD) is reported, a growing body of evidence supports a direct role for NAFLD in pathogenesis of atherosclerotic CVD (Sung et al, 2009).

Concerning the clinical presentations, easy fatigability, tender hepatomegaly and obesity (BMI) were significantly more frequent in NAFLD with predispo-sing factors than NAFLD alone, it was explained by elevated liver enzymes and lipid profile in that group. This study is also in consistent with Giday et al. (2006) who reported that in AfricanAmerican patients, the rate of obesity is increasing at a high rate. From the National Center for Health Statistics data (National Center for Health Statistics, 2005), 50\% of the African-American women are obese and $>60 \%$ of African-American adult men are overweight.

Regarding the elevated liver enzymes (ALT \& AST) as surrogate markers of NAFLD, were higher in NAFLD with predisposing factors than NAFLD alone and ALT $>$ AST. This result agreed with Esteghamati et al. (2010) who found that serum ALT and AST were significantly higher in patients with NAFLD with pre-disposing factors, elevated liver enzymes are associated with age, and this can be due to a mild underlying steatohepatitis, which is undetectable by ultrasound.

In the present study, with high fre-quency probes and a standardized pro-tocol to measure CIMT, the authors found that NAFLD cases were associated with CIMT but the presence of carotid plaques couldn't be found. NAFLD group with predisposing factors has higher carotid intimal media thickness (CIMT) $(0.72 \pm 0.14)$ than in NAFLD alone $(0.63 \pm 0.18)$ and more in obese $(0.72 \pm 0.10)$ than hyperlipedimic cases $(0.67 \pm 0.20)$ associated with NAFLD.

This data agreed with Targher et al. (2006) who found a significant increase in CIMT in the presence of non-alcoholic hepatic steatosis, and both conditions seemed to be due to visceral fat accumu-lation. It seems likely that abdominal obesity may be the common antecedent of both NAFLD and carotid atherosclero-sis, with the metabolic syndrome as an intermediate. Also, Kim et al. (2009) re-ported that the association between NAFLD and CIMT concerned only the patients with metabolic syndrome. On the other hand, it was proved that the same relationship might absent or present but largely explained by insulin resistance in type 2 diabetic patients (Michel et al. 2009).

Defining the role played by NAFLD in the formation of initial or advanced carotid lesions is beyond the scope of the present study, which was only designed to ascertain whether an incidental finding of NAFLD in outpatients may suggest the search for carotid lesions. A probable mechanistic explanation for the marked proatherogenic effect of NAFLD is the enhanced oxidative stress characteristic of this condition, which is believed to play a role in the progression from he-patic steatosis to steatohepatitis, fibrosis, and cirrhosis (Brunt, 2004).

NAFLD group with the predisposing factors was associated with increased CIMT especially with increasing the age and decreasing serum albumin level. That is mostly due to deterioration of the synthetic function of the liver.

In the current work, there was a statistically significant difference bet-ween the presence of bright hepatome-galy by abdominal ultrasound in NAFLD and CIMT by carotid duplex ultrasono-graphy. Brea et al. (2005) revealed that the diagnosis of NAFLD was based on the exclusion of known etiologic factors of liver disease and on the ultrasound examination but was not confirmed by liver biopsy for ethical reasons. However, ultrasound examination is by far the commonest 
way of diagnosing NAFLD in clinical practice and is very sensitive in the detection of the significant hepatic steatosis in patients with biopsy-proven disease (Saadeh et al, 2002).

The present study revealed a statistically significant relationship between the grades of steatosis and the presence of CIMT by carotid duplex ultrasonography. This agreed with Kim et al. (2009), who found an association between hepatic steatosis and carotid intimal media thickness. Also, Targher et al. (2006) study concluded that the severity of histo-pathological features in NAFLD is strongly associated with early carotid atherosclerosis, independent of classical risk factors, insulin resistance, and the presence of metabolic syndrome.

In another large cross-sectional study by Volzke et al. (2005) described an independent association of hepatic steatosis with carotid plaques, but not with CIMT. The discordance with this result might be due to the fact that those authors used low frequency $(5 \mathrm{MHz})$ US probes, which are known to provide less accurate CIMT measurements (Touboul et al. 2004). So, hepatic steatosis is a marker of increased CIMT in NAFLD group with predisposing factors.

NAFLD is a strong risk factor for the carotid atherosclerosis beyond its asso-ciation with MetS. The clinical corollary to the present study findings is that the casual detection of a fatty liver on abdo-minal ultrasound examination should alert to the probable existence of multiple underlying cardiovascular risk factors warranting evaluation and treatment as much as the risk for advancing liver disease (elKaraksy et al, 2011).

\section{Conclusion}

The etiology of NAFLD is the main leading factor for presence of CIMT as a sign of carotid atherosclerosis, mainly in those with bright liver by abdominal US and those with moderate steatosis by liver biopsy. Thus, it was recommended that any incidental finding of bright hepatomegaly by abdominal ultrasonography and lor hepatic steatosis by liver biopsy should prompt medical practition-ers not only to assess the metabolic risk (DM type II, hyper-lipedimia and lor obesity), but also to consider the search for silent carotid lesions.

\section{References}

Bates, JA, 2004: Pathology of the liver and portal venous system: In: Abdominal Ultrasound. How, Why and When? Chapter $4 ; 2^{\text {nd }}$ edition, edited by Bates, JA: Churchill Livingstone, Edinburgh, London, New York, Philadelphia, Toronto.

Brea, A, Mosquera, D, Martín, E, et al, 2005: Nonalcoholic fatty liver disease is associated with carotid atherosclerosis: a case-control study. Arterioscler. Thromb. Vasc. Biol. 25, 5:1045-50.

Brunt, .M, 2004: Nonalcoholic steatohepatitis. Semin. Liver Dis. 24, 1:3-20

Brunt, EM, Janney, CG, Di Bisceglie, AM, et al, 1999: Nonalcoholic steatohepatitis: a proposal for grading and staging the histolo-gical lesions. Am. J. Gastroenterol. 94:2467-74.

Chitturi, S, Wong, VW, Farrell, G, 2011: Nonalcoholic fatty liver in Asia: Firmly entrenched and rapidly gaining ground Hepatol. 226, 1:S163-72.

Choi, SY, Kim, D, Kang, JH, et al, 2008: Nonalcoholic fatty liver disease as a risk factor of ardiovascular disease: relation of non-alco-holic fatty liver disease to carotid atheroscle-rosis. [Article in Korean] Korean J. Hepatol. 14, 1:7788.

.Clark, JM, 2006: The epidemiology of nonalcoholic fatty liver disease in adults. J. Clin. Gastroenterol. 40, 1:S5-10.

Ekstedt, M, Franzen, LE, Mathiesen, UL, et al, 2006: Long-term follow-up of patients with NAFLD and elevated liver enzymes. Hepatology, 44, 4:865-73.

el-Karaksy, HM, el-Koofy, NM, Anwar, GM, el-Mougy, FM, el-Hennawy, A, et al, 2011: Predictors of non-alcoholic fatty liver disease in obese and overweight Egyptian children: single center study. Saudi J. Gastroenterol. 17, 1:40-6.

Esteghamati, A, Alireaza, A, Jamali, A, et al, 2010: Diabetology \& Metabolic Synd-rome. Vol. 2; PubMed Central; 10.1186/175- 8-5996$2-65$. 
Farrell, GC, Larter, CZ, 2006: Nonalcoholic fatty liver disease: from steatosis to cirrhosis. Hepatology, 43, 2/1:S99-112.

Fracanzani, AL, Burdick, L, Raselli, S, et al, 2008: Carotid artery intimamedia thickness in nonalcoholic fatty liver disease. Am. J. Med. 121, 1:72-8.

Giday, SA, Ashiny, Z, Naab, T, et al, 2006: Frequency of nonalcoholic fatty liver disease and degree of hepatic steatosis in AfricanAmerican patients. J. Natl. Med. Assoc. 98, 10: 1613-5

Grundy, SM, Brewer, HB, Cleeman, JI, et al, 2004: Definition of metabolic syndrome: Report of the National Heart, Lung, and Blood Institute/American Heart Association Confere-nce on Scientific Issues Related to Definition. Circulation, 109, 3:433-8.

Kim, HC, Kim, DJ, Huh, KB, 2009: Association between nonalcoholic fatty liver disease and carotid intima-media thickness according to the presence of metabolic syndrome. Atherosclerosis 204, 2: 521-5.

Kuntz, E, Dieter, H, 2006: Hepatology, Principles and Practice: History, Morphology, Biochemistry, diagnostics, clinic, therapy, the $2^{\text {nd }}$ edition

Marchesini, G, Marzocchi, R, 2007: Metabolic syndrome and NASH. Clin. Liver Dis. 11, 1:105-17.

Matteoni, CA, Younossi, ZM, Gramlich, T, et al, 1999: Nonalcoholic fatty liver disease: a spectrum of clinical and pathological severity. Gastroenterology 116, 6:1413-9.

Michel, PJ, Boris, G, Beatrice, T, et al, 2009: Non-alcoholic fatty liver is not associated with carotid intima-media thickness in type 2 diabetic patients. J. Clin. Endocrinol. Metab. 94: 4103-6

National Center for Health Statistics, 2005: Health, United States. www.cdc.gov/ nchs/data/ hus/hus05.

Olliff, JF, 2003: The liver and spleen, Chapter 25. In: Textbook of Radiology and Imaging, $\left(7^{\text {th }}\right.$ edition, Vol. 1), edited by Sutton, D, Robinson, PJ, Jenkins, JP, et al. Churchill Livingstone.

Palmentieri, B, De-Sio, I, La Mura, V, et al, 2006: The role of bright liver echo pattern on ultrasound B-mode examination in the diagnosis of liver steatosis. Dig. Liver Dis. 38, 7:485-9.

Preiss, D, Sattar, N, 2008: Non-alcoholic fatty liver disease: an overview of prevalence, diag- nosis, pathogenesis and treatment considerations. Clin. Sci. (Lond).115, 5:141-50.

Rocha, R, Cotrim, HP, Bitencourt, AG, et al, 2009: Nonalcoholic fatty liver disease in asymptomatic Brazilian adolescents. Wld. J. Gastroenterol. 15, 4:473-7.

Saadeh, S, Younossi, ZM, Remer, EM, et al, 2002: The utility of radiological imaging in nonalcoholic fatty liver disease. Gastroenterology123, 3:745-50.

Sanyal, AJ, 2002: AGA technical review on non-alcoholic fatty liver disease. Gastroenterology 123:1705-25.

Sung, KC, Ryan, MC, Wilson, AM, 2009: The severity of nonalcoholic fatty liver disease, is associated with increased cardiovascular risk in a large cohort of non-obese Asian subjects. Atherosclerosis 203, 2:581-6.

Targher, G, Bertolini, L, Padovani, R, et al, 2006: Non-alcoholic fatty liver disease is associated with carotid artery wall thickness in diet controlled type 2 diabetic patients. J. Endocrinol. Invest. 29, 1:55-60.

Touboul, PJ, Hennerici, MG, Meairs, S, et al, 2006: Mannheim carotid intima-media thickness consensus (2004-2006). An update on behalf of the Advisory Board of the $3^{\text {rd }} \& 4^{\text {th }}$ Watching the Risk Symposium, $13^{\text {th }} \& 15^{\text {th }}$ European Stroke Conferences, Mannheim, Germany, 2004, and Brussels, Belgium, 2006. Cerebrovasc. Dis. 23, 1: 75-80.

Volzke, H, Robinson, DM, Kleine, V, et al, 2005: Hepatic steatosis is associated with an increased risk of carotid atherosclerosis. Wld. J. Gastroenterol. 11, 12:1848-53.

WHO, 2006: Definition and Diagnosis of Diabetes Mellitus and Intermediate Hyperglycmia.www.who.int.2006.http://www.who.int/ diabe-

tes/publications/Definition\%2020and\%20diagno sis $\% 20$ of $\% 20$ iabetes_new.pdf.

WHO, 2010: BMI Classification. http://www who.int/bmi/index.jsp?introPageintrohtml..Willi am, BE, Clyde, HA, 2007: Fundamentals of Diagnostic Radiology: Vascular Ultrasound. Chapter $403^{\text {rd }}$ edition, Copyright Lippincott Williams \& Wilkins.

Williams, R, 2006: Global challenges in liver disease. Hepatology 44, 3:521-6. 


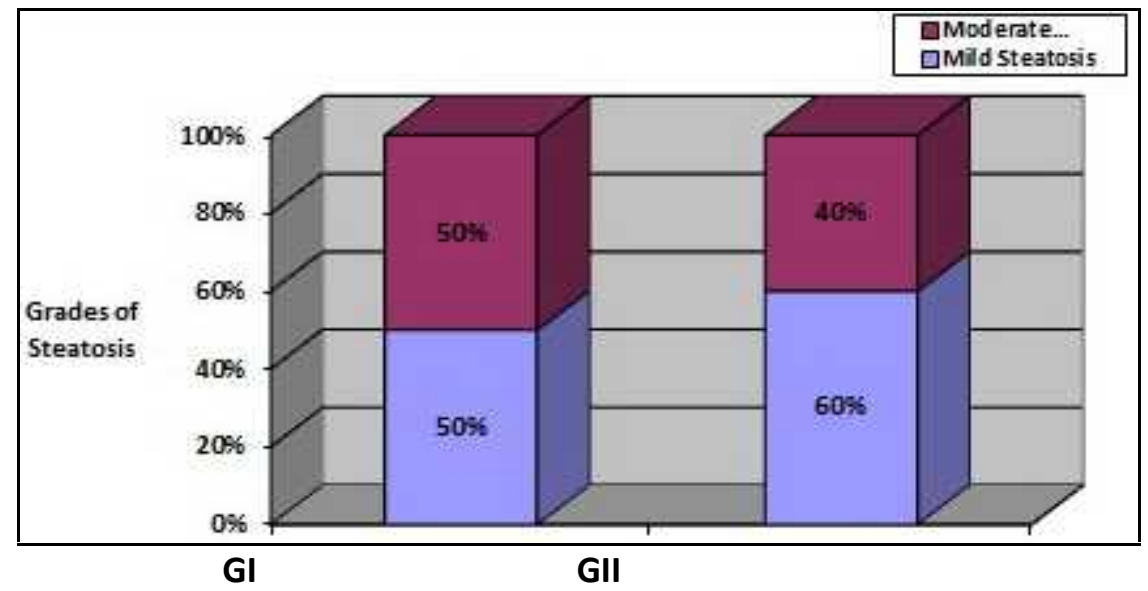

Figure 1: Comparison between GI \& II as regards Steatosis by Liver biopsy

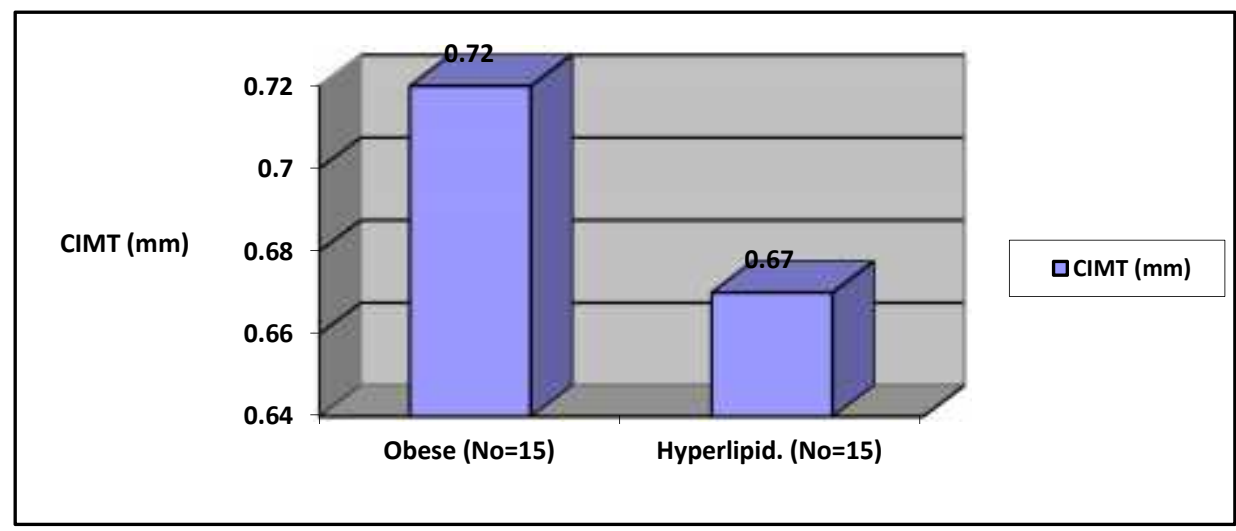

Figure 2: Comparison between obese and hyperlipedemic cases as regards carotid duplex ultrasonography

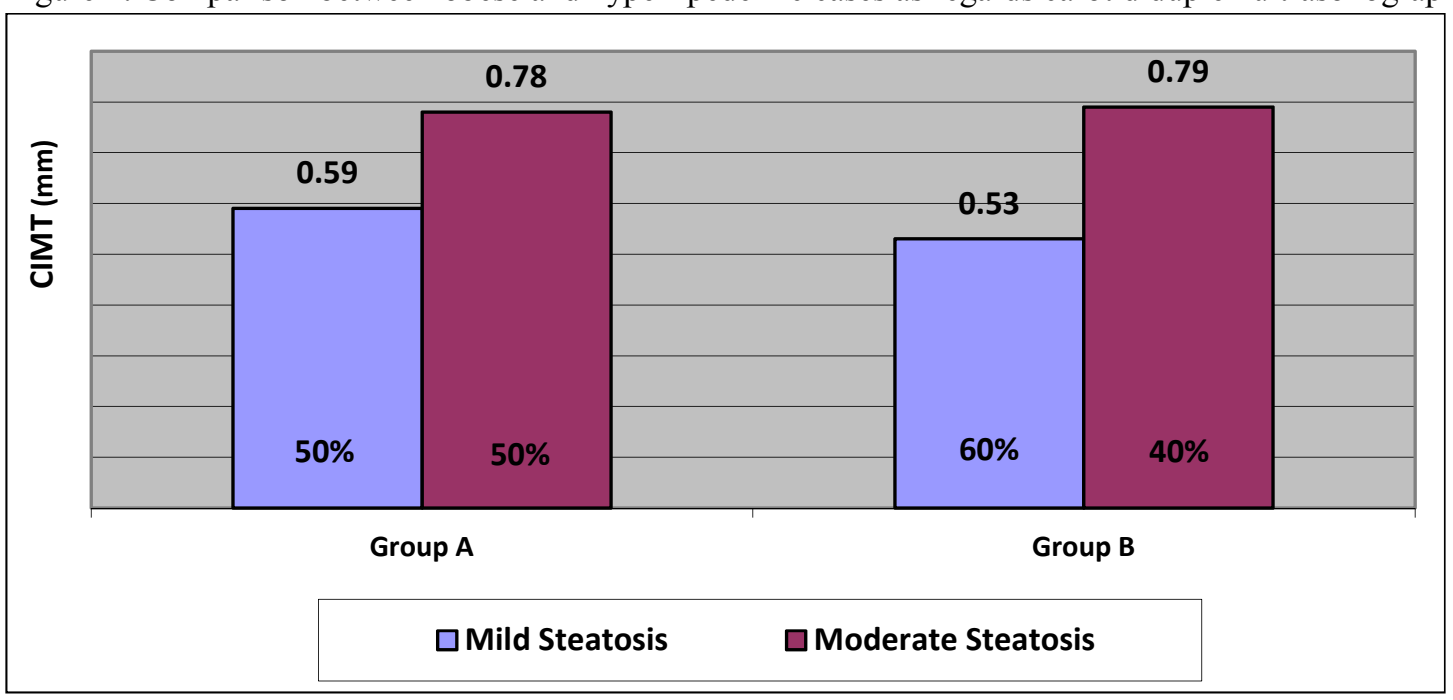

Figure 3: Comparison between grades of steatosis and CIMT in Gs I \& II 